\title{
Ocupação das escolas em 2015 e 2016: uma breve análise da forma e do conteúdo da ação dos estudantes
}

\author{
Daniel Leonel da Rocha ${ }^{1}$ \\ Recebido em maio de 2019 \\ Aceito em outubro de 2019
}

\section{RESUMO}

Este artigo tem por objetivo realizar uma breve análise da forma e do conteúdo da ação dos estudantes que ocuparam as escolas no ano de 2015 e 2016, a partir da maneira como foram representados em periódicos acadêmicos e imprensa. Para tanto, realizo uma revisão bibliográfica sobre o tema das ocupações, considerando dois tipos de fontes: artigos publicados em revistas acadêmicas e artigos e/ou notícias publicadas em dois jornais de grande circulação, O Globo e a Folha de São Paulo. Diante disso, considero três eixos de abordagem: i. a luta por uma educação pública de qualidade; ii. a utilização das redes sociais e aplicativos de mensagem como ferramenta de mobilização; iii. a disputa em torno do discurso sobre a legitimidade da ação dos estudantes. A hipótese defendida neste artigo é de que o processo de ocupação das escolas, representado em periódicos acadêmicos e imprensa, compõem um repertório de ação não convencional mobilizado em grande medida por valores pós-materialistas. Conforme a literatura dentro do campo da cultura política, esses valores estão orientados para uma postura pró-democracia.

Palavras-chaves: Ocupações; Estudantes; Formas-de-Ação; Valores-Políticos

\section{School occupation in 2015 and 2016: a brief analysis of student action}

\begin{abstract}
The purpose of this article is to briefly analyse the form and content of the actions of the students who occupied the schools in 2015 and 2016, based on the way they were represented in academic journals and the press. To this end, I carry out a literature review on the subject of occupations, resorting to two sources: articles published in academic journals and articles and/or news published in two newspapers of wide circulation, O Globo and Folha de São Paulo. Given this, I analyse three issues related to the students' occipations: i. the struggle for improcedent in public education; ii. the use of social networks and message applications as tools for mobilization; iii. the contest over the discourse on the legitimacy of student action. The hypothesis defended in this article is that the process of school occupation, represented in academic journals and press, compose a repertoire of unconventional action mobilized to a great extent by post-materialist values. According to the literature in the field of political culture, these values are oriented towards a pro-democracy perspective.
\end{abstract}

Keywords: Occupations; Students; Forms of action; Political Values

\section{O processo, a forma e o conteúdo da ação.}

1 Mestre em Ciências Sociais. Especialista em Políticas Públicas e Cultura de Direitos. Licenciatura em Filosofia. Contato: daniel.leonel.rocha@gmail.com. 
escolas, foi um movimento que utilizou a estratégia de ocupação de prédios públicos para reivindicar direitos essenciais. Além da atuação expressiva dos estudantes, as pautas que variavam de escola a escola trouxeram para o debate a necessidade de se repensar a educação pública. As primeiras ocupações datam de novembro de 2015 com início em São Paulo, replicando-se em Goiás, depois para o Rio de Janeiro e, quase concomitantemente, envolveu os estudantes do Espírito Santo, Minas Gerais, os estados da região sul, com destaque para o Paraná, e alguns da região nordeste e norte.

Identifico no decurso das ocupações duas ondas. A primeira, com auge no final de 2015, estava restrita às demandas de cada escola e foi protagonizada notadamente por secundaristas. A segunda, com auge em meados de 2016, incorporou pautas mais nacionais, como o protesto contra a PEC 241/16 (conhecida como a PEC do teto de gastos), o protesto contra a Reforma do Ensino Médio (Medida Provisória 746/2016) e o protesto contra a PL 867/2-15, conhecida como Escola sem Partido. Agora, os protagonistas não são somente secundaristas, mas também estudantes universitários. Amplia-se também a participação de estudantes em institutos tecnológicos, seja ocupando ou se mostrando solidários à causa. Não obstante, a mobilização dos estudantes não foi representativa para toda classe estudantil. Movimentos contrários às ocupações, como Desocupa Paraná3 apoiados pelo Movimento Brasil Livre (MBL) e o Direita Minas4, são exemplos disso. Após as eleições de 2018, diversos movimentos de direita se uniram para realizar o $\mathbf{1}^{\mathbf{0}}$ Encontro Nacional de Estudantes Conservadores (Unecon)5. Embora estas duas ondas tenham ocorrido em contextos distintos, interessa

${ }^{2}$ ROSSI, Marina. PEC 241: Com 1.000 escolas ocupadas no país, ato de estudantes chega a São Paulo. O GLOBO, Rio de Janeiro. 25 de out. de 2016. Disponível em: <http://noblat.oglobo.globo.com/geral/noticia/2016/10/pec-241-com-10oo-escolas-ocupadas-no-paisatode-estudantes-chega-sao-paulo.html>. Acesso em: o6 de jan. de 2018.

3 DANTAS, Tiago. Ocupação das escolas: todo cuidado para evitar conflitos. O GLOBO, Rio de Janeiro, o8 de nov. de 2016. Disponível em: <https://oglobo.globo.com/brasil/ocupacao-das-escolas-todocuidado-para-evitar-conflitos-20428907>. Acesso em: o6 de jan. de 2018.

4 ÉBOLI, Evandro. Em BH, novas escolas foram ocupadas após acordo com o TRE. O GLOBO, Rio de Janeiro, 29 de out. de 2016. Disponível em: < https://oglobo.globo.com/brasil/em-bh-novas-escolasforam-ocupadas-apos-acordo-com-tre-20382549>. Último acesso: o6 de jan. de 2018.

5 DANTAS, Dylan. No $1^{\circ}$ Encontro da UNECON - União Nacional dos Estudantes Conservadores, a Banda Sépia tocou a paródia "Bolsomito". Página Direita São Paulo, Sorocaba, 16 de mar. De 2019. Disponível em: <https://www.facebook.com/DireitaSaoPauloSorocaba/posts/no-1- 
neste artigo a maneira como as ocupações das instituições de ensino foram representadas em periódicos acadêmicos e imprensa, especificamente a forma de ação e os valores que foram partilhados.

No artigo Ocupação dos espaços públicos e a produção do comum: a ação política dos estudantes secundaristas nas escolas públicas de São Paulo, Rosemary Segurado e Marcelo Burgos (2016) destacam a motivação dos estudantes que se mobilizaram contra o projeto do Governo de São Paulo de fechamento de quase cem escolas, interferindo na vida de mais de trezentas mil pessoas. Embora esse não fosse o discurso da Secretaria de Educação do Estado de São Paulo, os autores enfatizaram que a ação de fechar escolas tinha por objetivo o corte de gastos com educação. Nesse contexto, a mobilização dos estudantes denunciou o plano do Estado, marcado pela lógica empresarial de contenção de despesas e metas por escola. A "produção do comum" que os autores trabalham no artigo se refere à constituição de novos espaços de atuação política, em que o sentido de cooperação é amplamente reforçado em duas esferas: "física", o local de vivência dos estudantes e de suas famílias, e "simbólica”, a disputa pelo discurso legitimador da ação dos jovens.

A pauta dos estudantes de São Paulo, no final de 2015, além de questionar o plano de fechamento e reorganização dos ciclos escolares, também contestavam as avaliações que mediam a qualidade do ensino nas escolas do estado. Os prêmios em dinheiro recebidos por escola dependiam da média alcançada pelos estudantes nessa prova. Essa política de incentivos, que, no olhar de Segurado e Burgos (2016), representa a lógica da competição, depõe contra a construção de relações de cooperação. Por isso, a ação dos estudantes paulistas pode ser ressaltada como marco social importante na luta pela construção do “comum”.

Segurado e Burgos (2016) descrevem o processo de ocupação das escolas pela sua forma descentralizada e crítica em relação às maneiras tradicionais de organização, com múltiplas redes de contatos e com performance semelhante a outros eventos ocorridos nos últimos dez anos. Merece destaque a coesão entre os estudantes, que não se reduz à

encontro-da-unecon-uni ${ }_{0} \mathrm{C}_{3} \% \mathrm{~A}_{3} 0$-nacional-dos-estudantes-conservadores-a-bandas\%C3\%A9pi/2088852721234567/>. Acesso em: 20 de abr. de 2019. 
pauta de ação, mas se estende aos valores políticos compartilhados, desdobrados na forma de organização caracterizada por comissões e assembleias.

No artigo A dimensão espacial da escola pública: leituras sobre a reorganização da rede estadual de São Paula, Eduardo Donizeti Girotto (2016, p. 1123-1125) aborda duas perspectivas do movimento das ocupações. Da parte dos estudantes, a característica de “autogestão, ação direta, apoio mútuo e solidariedade”. Conforme estudo do autor, as características levantadas sobre o movimento dos estudantes podem ser encontradas nas formas históricas de organização dos coletivos das periferias de São Paulo ("redes de sociabilidades”), cuja pauta reivindica “direitos básicos de cidadania”. Ele ainda afirma que a escola pública é o lugar estratégico de presença do Estado, na conformação ideológica de sua identidade (periferias) e, principalmente, naquilo que ele chamou de "gestão da pobreza” (programas sociais). Dessa maneira, a sua primeira hipótese considera que na mobilização, os estudantes, com suporte dos coletivos das periferias, se manifestaram contra o distanciamento do Estado, pela ausência de diálogo, pela péssima qualidade da educação e, por fim, pelo plano de reconfiguração das escolas e dos ciclos escolares, que afetaria a vida de milhares de pessoas. Por isso, não se pode pensar num plano de educação sem considerar os impactos socioespaciais que dele podem resultar. Da parte do Governo do Estado de São Paulo, destaca os interesses públicos e privados no fechamento e reorganização das escolas. Girotto (2016) trabalha com a hipótese de que o fechamento das escolas em São Paulo se articula com "o avanço de processos de produção e valorização do espaço urbano” (p. 1129). Segundo ele, algumas escolas, em locais centrais de São Paulo, foram fechadas e reutilizadas tanto para fins administrativos (em posse do governo) como para fins imobiliários (venda de patrimônio público para interesse privado). Para tanto, o autor cita reportagem do dia 07/11/2015, do Diário de São Paulo. Logo após a divulgação da lista das escolas que seriam fechadas pelo novo projeto do governo, ele verificou, em sua pesquisa, elevado número de lançamentos imobiliários no entorno das escolas que seriam fechadas. Conclui que essas coincidências colocam em dúvida "as reais intenções presentes no projeto de reorganização escolar" (GIROTTO, 2016, p. 1131).

No artigo Ocupar e resistir: a insurreição dos estudantes paulistas, Ana Paula de Oliveira Corti et al. (2016) destacam três maneiras de abordar o tema: o primeiro, pela 
leitura sociológica da cultura juvenil, o segundo, pela leitura psicológica da categoria "adolescência" e "juventude", o terceiro, por abordagens de cunho metodológico que visam a aproximar o conteúdo curricular da realidade dos estudantes. Segundo os autores, esses enfoques visam a produzir um discurso que reconheça os jovens como "sujeitos peculiares, que demandam a organização de um saber-fazer educativo próprio que dialogue com as suas especificidades" (CORTI et al., 2016, p. 1.166). Nesse sentido, as ocupações representam a tentativa de recriar espaços para organização de um saberfazer educativo próprio. Ana Paula de Oliveira Corti et al. (2016, p. 1168-1171) enfatizam algumas características das ocupações, como a utilização das redes sociais para difusão do movimento, "a preocupação em não reproduzir estereótipos de gênero na escolha das comissões", com protagonismo das jovens na condução da maioria das ações, e a oferta de atividades culturais como shows, sarais e aulas públicas. Por isso, a forma de condução das ocupações mostra o desejo dos estudantes por novas metodologias de aprendizagem. Ao mesmo tempo, enfatiza a capacidade do estudante de participar e influir nas decisões tomadas no ambiente escolar. Segundo os autores, "as imagens oferecidas pelos jovens nas ocupações - atuando, discursando, cozinhando e limpando contrastam com as imagens tradicionais de estudantes calados e enfileirados nas salas de aula" (CORTI et al., 2016, p. 1171).

No artigo, Ocupar, resistir e a luta nas redes sociais, Sílvio Carneiro (2017) argumenta que as redes sociais, no caso das ocupações das escolas, forneceram o diagnóstico do presente, ao "conferir um mapa de deslocamentos dos significantes em disputa pelos quais mobilizam novos elementos que fazem da pesquisa social uma experiência de emancipação" (p. 138). As ocupações das escolas não foram o momento do início do movimento dos estudantes, mas a culminância da mobilização que começou nas redes de Whatsapp, Facebook e no convívio escolar. Por isso, as redes sociais podem ser consideradas como instrumento fundamental para convocação e manutenção dos atos dos estudantes, entre 2015 e 2016.

As ocupações, no olhar de Sílvio Carneiro (2017), representam a quebra dos modelos associativos que comumente articulam mobilizações. A figura do líder estudantil, dos movimentos estudantis organizados como UNE e Ubes, a exigência de um comitê de representação responsável por negociar com o governo; todas essas 
estruturas de oportunidades foram relativizadas com o protagonismo da rede de relações on-line. E como a sociedade em rede não possui um centro, ou estrutura central, as ocupações das escolas reproduziram as relações on-line no cotidiano off-line.

Esse mesmo autor considera que as redes de contatos on-line se tornaram importantes por dois motivos: primeiro, por ser instrumento de domínio dessa geração de adolescentes e jovens; segundo, porque são importantes "em uma instituição avessa a assembleias, grêmios estudantis, conselhos de escola de fato etc. Meios de comunicação subterrâneos em uma instituição contrária a comunicados que não venham das instâncias do poder oficial, bem como esvaziada de espaços públicos de decisão" (CARNEIRO, 2017, p.140). O aspecto interessante na ação dos estudantes, ausentes as estruturas de oportunidades políticas - assembleias, grêmios estudantis, conselhos de escola -, é a construção de outras alternativas de ação por via das redes sociais. Devido às características próprias das redes on-line, a flexibilidade, a velocidade e a horizontalidade, incorporam-se performances diversas e atualizam-se rapidamente os repertórios de ação. O que se amplia é o escopo dos repertórios de disputa que, segundo Tilly (2006, p. VII apud CARNEIRO, 2017, p. 141), são “os arranjos de performances de ações de protesto limitados, familiares e criados historicamente, os quais, sob diversos aspectos, circunscrevem os meios pelos quais as pessoas se engajam em políticas de disputa”. As redes on-line favorecem a ampliação dos arranjos de performances de ações de protesto.

No artigo Ocupações dos secundaristas do RS: tensões culturais $e$ reconfigurações comunicativas, Rosário et al (2016) entendem que a mobilização dos estudantes se conforma "como textos culturais a partir de suas diversas manifestações (...) acumulam, transmitem e movimentam sentidos" (p. 195-196), tudo isso dentro do contexto de carência de apoio de muitos pais, professores e colegas de escola. Ao mesmo tempo, informações desencontradas nas redes sociais e na mídia oficial quase sempre associam as ocupações das escolas com partidos e movimentos estudantis organizados. Por isso, garantir a legitimidade do movimento dos estudantes é afirmar sua autonomia.

Rosário et al. (2016) trabalham com a hipótese de que a convergência de tensões ou interesses, caso do conjunto de ocupações das escolas, é condição para construção de novos discursos. As ações de todas as partes são de cunho afirmativo, autoexpressivo, 
característica das recentes estruturas de mobilização no Brasil. Os autores abordam os conflitos a partir do que entendem por fronteira que "delimita o espaço dos diferentes sistemas" e "marca os espaços de cada conjunto" ou grupos em questão (ROSÁRIO et al., 2016, p. 197). O aspecto interessante da abordagem trazida pelo artigo de Rosário et al. é o entendimento de que a estratégia de ação cultural - sarais, shows, oficinas - aliada às ferramentas das redes sociais, constituíram o canal alternativo para produção do discurso.

Para critério de reflexão, indico um quadro que representa de maneira geral a relação entre a forma e o conteúdo da ação dos estudantes que ocuparam as escolas.

Quadro 1 - Relação entre a estratégia, a forma e os valores compartilhados no processo de ocupações das escolas.

\begin{tabular}{ccc}
\hline Estratégia de ação & Forma de ação & Valore partilhados \\
\hline $\begin{array}{c}\text { Ocupação das } \\
\text { escolas }\end{array}$ & $\begin{array}{c}\text { Decisões tomadas de maneira coletiva } \\
\text { por meio de assembleia } \\
\text { Divisão dos serviços e a busca } \\
\text { pela igualdade de gênero } \\
\text { Trancaços das ruas } \\
\text { Passeatas nas ruas }\end{array}$ & Horizontalidade \\
Resistentes quanto à interferência \\
Ativismo on-line & $\begin{array}{c}\text { Aulas e oficinas temáticas e atividades } \\
\text { culturais }\end{array}$ & Igualdade \\
\hline
\end{tabular}

Fonte: Compilação do autor ${ }^{6}$

2. Observações sobre as notícias e os artigos publicados em dois jornais de grande circulação

Além dos aspectos levantados anteriormente nos artigos acadêmicos, acrescento aqui notícias veiculadas em duas fontes, os jornais $O$ Globo e Folha de São Paulo, que apresentam visões ora divergentes, ora convergentes sobre o movimento dos estudantes que ocuparam as escolas. Nos artigos e notícias pesquisados, destaco seis itens: i. como as ocupações foram nomeadas; ii. como o poder público reagiu; iii. a estratégia dos estudantes; iv. o nexo entre as ocupações, as manifestações de junho de

${ }^{6}$ Montagem a partir da forma como as ocupações das instituições de ensino foram representadas em periódicos acadêmicos e imprensa. 
2013 e o movimento dos estudantes chilenos; v. a agenda de discussões; vi. o balanço das vitórias e derrotas dos estudantes.

\section{Como as ocupações foram nomeadas?}

Em publicação do dia 24/11/20157, a reportagem da Folha de São Paulo chamou de "invasão" o ato dos estudantes em São Paulo. Até a data dessa publicação, já eram 109 escolas ocupadas no estado de São Paulo. Os estudantes secundaristas se mobilizaram em protesto contra o fechamento e reestruturação de 92 escolas, interferindo diretamente na vida de aproximadamente 311 mil estudantes. Devido à extensão do ato dos estudantes e ao apoio do Tribunal de Justiça de São Paulo, que negou a reintegração de posse das escolas ocupadas, as publicações que se sucederam sobre o tema passaram a utilizar o termo "ocupação".

O jornal $O$ Globo não documentou de maneira tão ampla o ato dos estudantes paulistas, como o fez a Folha de São Paulo. Mesmo assim, em publicação 24/11/2015 ${ }^{8}$, Globo destacou a negativa da justiça para reintegração de posse das escolas tomadas e enfatizou no conteúdo do parecer de que "as ocupações não envolvem questões de posse, uma vez que o objetivo dos estudantes é discutir a proposta do Estado para o ensino".

Numa análise comparativa, a Folha de São Paulo se dedicou a apresentar o avanço das ocupações, que tiveram início em novembro de 2015 e depois se expandiu para outros 18 estados da federação. Sempre caracterizou o movimento dos estudantes pela forma de atuação - ocupação das escolas e "trancaços" nas ruas movimentadas de São Paulo -, pela organização interna - as comissões por área de serviço e as assembleias - e pelas atividades durante o processo de ocupação - as aulas públicas, os eventos culturais, as oficinas temáticas. Para isso, frequentemente fizeram visitas e

7 Estudantes ocupam escola estadual na zona leste de São Paulo. FOLHA DE SÃO PAULO, São Paulo, 24 de nov. de 2015. Disponível em: <https://www1.folha.uol.com.br/educacao/2015/11/1710194estudantes-ocupam-escola-estadual-na-zona-leste-de-sao-paulo.shtml?loggedpaywall>. Acesso em: $06 \mathrm{de}$ jan. 2018.

${ }^{8}$ Justiça de SP nega pedido de reintegração de posse de escolas. O GLOBO, Rio de Janeiro, 23 de nov. de 2015. Disponível em: <http://noblat.oglobo.globo.com/geral/noticia/2015/11/justica-de-sp-negapedido-de-reintegracao-deposse-de-escolas.html>. Acesso em: o6 de jan. de 2018. 
entrevistaram diversos estudantes, como também acompanharam de perto os atos nas ruas de São Paulo. O jornal O Globo, por sua vez, dedicou-se a noticiar as ocupações sempre relacionado com suas consequências práticas, como, por exemplo, o transtorno causado aos motoristas e pedestres em caso de "trancaço" nos cruzamentos das vias centrais da cidade de São Paulo; mudança ou adiamento de provas de vestibular (Fuvest) e Exame Nacional do Ensino Médio (Enem) em escolas onde ocorreriam as avaliações; o dilema sobre o processo eleitoral em 2016 nas escolas que funcionavam como seção e que estavam ocupadas. Essas ênfases foram pouco encontradas nas notícias da Folha.

\section{Como o poder público reagiu?}

Marisa von Bülow9 (2015) ressalta quatro estratégias comumente utilizadas pelos governos para vencer manifestações sociais: 1) deslegitimar o movimento; 2) afirmar que são manipulados por agentes externos (partidos); 3) ignorar; 4) reprimir.

Quanto à primeira estratégia, ambas as fontes pesquisadas destacam a intenção dos governos em deslegitimar o ato dos estudantes. Acusam-nos de depredação do patrimônio público, de não estarem abertos ao diálogo e que não sabem pelo que estão se mobilizando. A Folha de São Paulo, em publicação do dia 08/11/2016 ${ }^{10}$, praticamente um ano após o início das ocupações no Brasil, destacava a fala do presidente Temer, quando discursou afirmando que os estudantes protestam sem fundamento; evitando utilizar a palavra "estudantes", o presidente preferiu dizer "desses que ocupam". O jornal $O$ Globo, em publicação do dia $08 / 11 / 2016^{11}$, também registrou a crítica do presidente às ocupações e concluiu ao citá-lo: "Hoje, ao invés do argumento moral, intelectual, verbal, usa-se o argumento físico. Vai e ocupa não sei o quê, bota pneu velho, queima, fecha o trânsito".

9 BÜLOW, Marisa Von. O novo movimento estudantil e suas lições. O GLOBO, Rio de Janeiro, 16 de dez. de 2015. Disponível em: <http://noblat.oglobo.globo.com/artigos/noticia/2015/12/o-novomovimento-estudantil-e-suas-licoes.html>. Acesso em: o6 de jan. de 2018.

${ }^{10}$ Ironia de Temer ao atacar ocupações gera reação de entidades estudantis. FOLHA DE SÃO

PAUlO, São Paulo, o8 de nov. de 2016. Disponível em: $<$ https://wwwi.folha.uol.com.br/educacao/2016/11/1830604-ironia-de-temer-ao-atacar-ocupacoes-gerareacao-de-entidades-estudantis.shtml>. Acesso em: 06 de jan. de 2018.

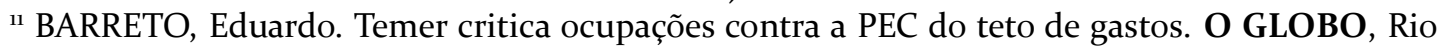
de Janeiro, o8 de nov. de 2016. Disponível em: <https://oglobo.globo.com/brasil/temer-critica-ocupacoescontra-pec-do-teto-de-gastos-20430164>. Acesso em: o6 de jan. de 2018. 
O recém-eleito deputado federal por São Paulo, Kim Kataguiri, líder do Movimento Brasil Livre (MBL), que ganhou notoriedade durante as articulações políticas para o impeachment de Dilma Rousseff ${ }^{12}$, escreveu na coluna da Folha de São Paulo, no dia 17/05/2016, ${ }^{13}$ que o movimentos dos estudantes se caracterizaram pela “ocupação dos desocupados”. Dentre as acusações feitas por Kataguiri, estão: aliciamento dos estudantes por partidos políticos e entidades estudantis vinculadas à esquerda (Ubes e UNE) e crimes como roubo - dinheiro, notebooks, telefones, pendrives -, arrombamento de gavetas e armários, depredação de portas e equipamentos. Aqui, o colunista se refere ao caso de uma escola técnica de São Paulo. O MBL atuou organizando setores que eram contrários às ocupações, principalmente no Paraná, estado com maior número de ocupações em todo o Brasil (840 escolas aproximadamente). Os principais embates se deram pelas redes sociais, com textos e vídeos favoráveis ou contrários às ocupações.

Quanto à segunda estratégia, em reportagem do dia 11/10/2016 ${ }^{14}$, o governador do Paraná, Beto Richa, afirmou que sindicatos e partidos "usam de forma criminosa as nossas crianças das escolas, que estão nas ruas protestando não sabem nem por que, em uma perfeita doutrinação ideológica”. Essa fala foi reproduzida em outros contextos pelas autoridades políticas dos estados com escolas ocupadas. Em Goiás, a secretaria de educação disse que as ocupações são fruto de uma "confusão ideológica em relação às OS”. Os estudantes goianos se mobilizaram em protesto contra o plano do governador Marconi Perillo de transferir a gestão das escolas ocupadas para Organizações Sociais. Perrilo afirmou, conforme notícia da Folha de São Paulo, que "há o debate radical contra, de pessoas de fora das escolas, que não querem acabar com o status quo, com

${ }^{12}$ DANTAS, Tiago. Ocupações no Paraná sofrem pressão de pais e do MBL. O GLOBO, Rio de Janeiro, 03 de nov. de 2016. Disponível em: <https://oglobo.globo.com/brasil/ocupacoes-no-paranasofrem-pressao-de-pais-do-mbl-20403401>. Acesso em: o6 de jan. de 2018.

${ }^{13}$ KATAGUIRI, Kim. A ocupação dos desocupados. FOLHA DE SÃO PAULO, São Paulo, 17 de maio de 2016. Disponível em: <http://www1.folha.uol.com.br/colunas/kim-kataguiri/2016/o5/177180o-aocupacao-dosdesocupados.shtml>. Acesso em: o6 de jan. De 2018.

${ }^{14}$ TERENZI, Gabriela; SALDAÑA, Paulo. Fortalecidos após ocupações, secundaristas de SP renegam entidades estudantis. FOLHA DE SÃO PAULO, São Paulo, o3 de jul. de 2016. Disponível em: <https://www1.folha.uol.com.br/saopaulo/2016/o7/1787761-fortalecidos-apos-ocupacoes-secundaristasde-sp-renegam-entidades-estudantis.shtml>. Acesso em: 06 de jan. de 2018. 
corporativismo e sindicalismo"15. O governador Geraldo Alckmin afirmou que "é nítido que há uma ação política do movimento"16.

Da parte dos estudantes, a acusação de que há interferência de partidos e movimentos organizados foi negada. Em reportagem do dia 01/12/2015, ${ }^{17}$ a Folha de São Paulo destacava a fala dos estudantes: "não temos líderes, aqui é um coletivo, e as decisões são tomadas a partir de votações nas assembleias. Não entra adulto ou professor, apenas aluno”. A única instância de representação do movimento era o “Comando das Ocupações". Como forma de afirmar a horizontalidade do movimento, mesmo pela instância de representação, os estudantes realizavam jograis "para evitar que se caracterizasse a presença de alguma liderança"18.

Quanto à terceira estratégia - ignorar o movimento dos estudantes - não obteve sucesso, ao menos em São Paulo, onde ocorreram as primeiras ocupações, no Rio de Janeiro, o terceiro estado a registrar ocupações, e nos estados da região sul do Brasil. Nos territórios mencionados, foram mais de mil escolas ocupadas. O presidente Temer só se pronunciou publicamente sobre as ocupações em novembro de 2016, pouco mais de um ano depois de a primeira escola ter sido ocupada em São Paulo. O jornal O Globo cita a fala do presidente nos seguintes termos: "a pior coisa é quando acontece isso (ocupações) e você dá importância”'19.

As ocupações das escolas em São Paulo foram precedidas por atos de pais, alunos e servidores que protestavam contra a reorganização das escolas, anunciada em

\footnotetext{
${ }^{15}$ BATISTA, Diene. Em Goiás, alunos de escolas ocupadas pedem doações para a ceia de Natal. FOLHA DE SÃO PAULO, São Paulo, 23 de dez. de 2015. Disponível em: $<$ https://www1.folha.uol.com.br/educacao/2015/12/1722519-em-goias-alunos-de-escolas-ocupadaspedem-doacoes-para-a-ceia-de-natal.shtml>. Acesso em: o6 de jan. de 2018.

${ }^{16}$ SANTIAGO, Tatiana. 'Há uma nítida ação política', diz Alckmin sobre protestos de alunos. $\mathbf{O}$ GLOBO, Rio de Janeiro, o2 de dez. de 2015. Disponível em: <http://g1.globo.com/saopaulo/noticia/2015/12/ha-uma-nitida-acao-politica-diz-alckmin-sobre-protestos-de-alunos.html>. Acesso em: 10 de jun. de 2018.

${ }^{17}$ Há um mês na escola, alunos limpam, cozinham e até instalam chuveiros. FOLHA DE SÃO

PAUlO, São Paulo, o1 de dez. de 2015. Disponível em: <https://wwwl.folha.uol.com.br/educacao/2015/12/1712999-ha-um-mes-nas-escolas-alunos-organizamlimpam-cozinham-e-ate-instalam-chuveiros.shtml>. Acesso em: o6 de jan. de 2018.

${ }^{18}$ RODRIGUES, Artur. Após recuo de Alckmin, estudantes decidem manter ocupação em escolas. FOLHA DE SÃO PAULO, São Paulo, 04 de dez. de 2015. Disponível em: <https://wwwi.folha.uol.com.br/educacao/2015/12/1715267-apos-recuo-de-alckmin-estudantes-decidemmanter-ocupacao-em-escolas.shtml>. Acesso em: o6 de jan. de 2018.

19 BARRETTO, Eduardo. Temer critica 'vandalismo' de protesto contra teto de gastos. O GLOBO, Rio de Janeiro, 29 de nov. de 2016. Disponível em: <https://oglobo.globo.com/economia/temercritica-vandalismo-de-protesto-contra-teto-de-gastos-20563377>. Acesso em: o6 de jan. de 2018.
} 
setembro de 2015, pela Secretaria de Educação. A queixa principal era de que a Secretaria de Educação não dialogava com a comunidade escolar. Isso se verifica pela fala do estudante que participou da segunda escola que foi ocupada, a Escola Estadual Fernão Dias: "a gente viu que os protestos não estavam dando certo. Resolvemos radicalizar" A Secretaria de Educação, que sempre afirmou estar aberta ao diálogo, estabeleceu a estratégia de mutirão de visitas às ocupações, com intuito de requerer as reivindicações de cada colégio ${ }^{21}$. O procedimento de reivindicação deveria ser formalizado por meio de carta. Os agentes que visitavam a escola tinham em mãos um documento com a seguinte orientação: "Requeremos o envio das reivindicações e agendamentos com a autoridade da Diretoria de Ensino (...) para realização de reuniões”. Os alunos deveriam assinar o requerimento. Essa estratégia foi vista com maus olhos pelos estudantes e apoiadores do movimento de ocupações, dita como falsa negociação. Segundo reportagem da Folha de São Paulo ${ }^{22}$, entendia-se que, com essa medida, se enfraquecia o ato dos estudantes, ao classificá-los como intransigentes.

Em Goiás, segundo estado a registrar ocupações, a estratégia de ignorar o movimento surtiu mais efeito. Caso exemplar foi o tratamento dado pela Secretaria de Educação para primeira escola a ser ocupada, o Colégio Estadual José Carlos de Almeida, símbolo para o movimento de ocupações dos estudantes goianos: "Há um ano, ela já não é mais escola, estava vazia. Não teve nenhum aluno ao longo de 2015 ”23. Por isso, não é considerada para o saldo das ocupações. Em outra fala, a Secretaria de Educação se pronunciou da seguinte maneira: "esse movimento de ocupação de escolas da rede é

${ }^{20}$ MACHADO, Leandro. Inspirado no Chile, manual orientou ocupação de escolas por alunos em SP. FOLHA DE SÃO PAULO, São Paulo, 25 de nov. de 2015. Disponível em: <https://www1.folha.uol.com.br/educacao/2015/11/1710710-inspirado-no-chile-manual-orientouocupacao-de-escolas-por-alunos-em-sp.shtml>. Acesso em: o6 de jan. de 2018.

${ }^{21}$ GRAGNANI, Juliana. Governo de SP usa formalidade para propor conversa com aluno. FOLHA

DE SÃO PAULO, São Paulo, o1 de dez. de 2015. Disponível em: <https://www1.folha.uol.com.br/educacao/2015/12/1713268-governo-de-sp-usa-formalidade-para-proporconversa-com-aluno.shtml>. Acesso em: o6 de jan. de 2018.

${ }^{22}$ Alunos a favor de ocupações de escolas liberam av. Faria Lima após 3 horas. FOLHA DE SÃO

PAULO, São Paulo, 30 de nov. de 2015. Disponível em: <https://www1.folha.uol.com.br/educacao/2015/11/1712838-por-ocupacao-em-escolas-paulistas-grupointerdita-av-faria-lima-em-sp.shtml>. Acesso em: o6 de jan. de 2018.

${ }^{23}$ Batista, Diene. Em Goiás, alunos ocupam escolas no interior contra 'terceirização'. FOLHA

DE SÃO PAULO, São Paulo, 14 de dez. de 2015. Disponível em: $<$ https://www1.folha.uol.com.br/cotidiano/2015/12/1718878-em-goias-alunos-ocupam-escolas-nointerior-contra-terceirizacao.shtml>. Acesso em: o6 de jan. de 2018. 
extemporâneo, injustificável e desnecessário"24. Segundo o governador Marconi Perillo, ele não iria politizar as ocupações. Ao todo, registraram-se aproximadamente 29 ocupações em todo estado, conforme a Folha de São Paulo ${ }^{25}$.

Quanto à quarta estratégia, a repressão, a violência policial foi amplamente registrada pelas reportagens. Em publicação do dia 27/11/2015, a Folha de São Paulo registrou a iniciativa da "ONG Minha Sampa", que criou uma rede de contatos denominada "De guarda pelas escolas", com o intuito de mobilizar pessoas em caso de desocupação forçada. Até novembro de 2015, já havia 1.500 pessoas cadastradas. Segundo a ONG, essa rede servia "para proteger as escolas da truculência da polícia, com o seu corpo, sua voz, sua câmera e sua indignação”. Não por acaso, existem diversos vídeos postados na Internet e documentários que registram a repressão que os estudantes sofreram. Mais do que o corpo a corpo, o poder de uma câmera inibe ações de extrema violência.

Em reportagem do dia 26/03/2016 26 , a Folha de São Paulo publicou a iniciativa dos estudantes paulistas, junto com o "Comitê de Mães e Pais em Luta" e a "ONG Artigo 19", de fazer uma denúncia formal à Organização de Estados Americanos (OEA), instância responsável pela garantia dos direitos humanos para as Américas. O conteúdo da denúncia se referia aos excessos cometidos pela Política Militar do Estado de São Paulo na repressão aos estudantes. Além do texto, foram gravadas diversas imagem que documentaram as ações policiais.

Três fatos repercutiram entre os estudantes que ocuparam as escolas. O primeiro se refere à estudante Mariana, que foi agredida por um motorista em um ato

\footnotetext{
${ }^{24}$ Batista, Diene. Contra plano de governador tucano, estudantes ocupam escolas de Goiânia. FOLHA DE SÃO PAULO, São Paulo, 11 de dez. de 2015 . Disponível em: <https://wwwi.folha.uol.com.br/educacao/2015/12/1717898-contra-plano-de-governador-tucanoestudantes-ocupam-escolas-de-goiania.shtml>. Acesso em: o6 de jan. de 2018.

${ }^{25}$ Amâncio, Thiago. Estudantes deixam três das últimas escolas ocupadas em GO, diz governo. FOLHA DE SÃO PAUlO, São Paulo, 21 de fev. de 2016. Disponível em: $<$ https://www1.folha.uol.com.br/educacao/2016/o2/1741686-estudantes-deixam-tres-das-ultimas-escolasocupadas-em-go-diz-governo.shtml>. Acesso em: 06 de jan. de 2018.

${ }^{26}$ Bergamo, Monica. Estudantes de ocupações fazem vídeo para denunciar governo de SP à

OEA. FOLHA DE SÃO PAULO, São Paulo, 23 de mar. De 2016. Disponível em: $<$ https://www1.folha.uol.com.br/colunas/monicabergamo/2016/03/1754172-estudantes-de-ocupacoesfazem-video-para-denunciar-governo-de-sp-a-oea.shtml>. Acesso em: o6 de jan. de 2018.
} 
em São Paulo ${ }^{27}$. A jovem levou um soco no queixo dado por um motorista, que ficou furioso pelo protesto que fechou as avenidas Rebouças e Faria Lima. A fala da jovem, publicada pela Folha de São Paulo, afirmava: "o que me deixou mais triste foi que a agressão veio da população. Normalmente, vem da polícia”. Além da agressão, a jovem recebeu xingamentos como "puta" e "vagabunda". Todas as ofensas e a agressão foram filmadas. O segundo fato é a tragédia ocorrida em Goiás. O pai, que se dizia contrário à participação do filho nas ocupações das escolas, o matou e logo depois se suicidou. O fato comoveu amigos e familiares e chamou a atenção da opinião pública ${ }^{28}$. O terceiro fato foi a morte de um estudante no Paraná, durante umas das ocupações. Segundo publicação da Folha de São Paulo²9, o jovem de 16 anos foi morto a facadas por outro colega, de 17 anos.

\section{Estratégia de ação dos estudantes?}

As redes sociais e as passeatas pelas ruas foram o principal instrumento de contato e articulação dos estudantes. Em reportagem do dia 25/11/2015, a Folha de São Paulo resume como se deu o início do movimento em São Paulo: “Até o fim de Outubro os protestos contra a medida de Alckmin estavam restritos a passeatas de rua (...) Alunos de escolas diferentes - e que se conheceram nas passeatas - criaram grupos de Whatsapp para discutir maneiras de barrar a reorganização dos ciclos”3o. Foi em um dos grupos de Whatsapp que surgiu o manual sobre como ocupar uma escola.

27 MACHADO, Leandro. Não vai mais a protesto sozinha, afirma mãe de aluna agredida. FOLHA DE SÃO PAUlO, São Paulo, o9 de dez. de 2015. Disponível em: <https://www1.folha.uol.com.br/educacao/2015/12/171668o-nao-vai-mais-a-protesto-sozinha-afirmamae-de-aluna-agredida.shtml>. Acesso em: o6 de jan. de 2018.

${ }_{28}^{8}$ JULIÃO, Luis Guilherme. Pai matou filho por ter participado de ocupação em Goiânia, diz família. O GLOBO, Rio de Janeiro, 16 de nov. de 2016. Disponível em: <https://oglobo.globo.com/brasil/pai-matou-filho-por-ter-participado-de-ocupacao-em-goianiadizfamilia-20474139>. Acesso em: o6 de jan. de 2018.

29 Brasil tem 1.154 unidades de ensino ocupadas por alunos, diz entidade. FOLHA DE SÃO

PAULO, São Paulo, 26 de out. de 2016. Disponível em: <https://www1.folha.uol.com.br/educacao/2016/10/1826548-brasil-tem-1154-unidades-de-ensinoocupadas-por-alunos-diz-entidade.shtml>. Acesso em: o6 de jan. de 2018.

$3^{\circ}$ MACHADO, Leandro. Inspirado no Chile, manual orientou ocupação de escolas por alunos

em SP. FOLHA DE SÃO PAULO, São Paulo, 25 de nov. de 2015. Disponível em: $<$ https://www1.folha.uol.com.br/educacao/2015/11/1710710-inspirado-no-chile-manual-orientou-

ocupacao-de-escolas-por-alunos-em-sp.shtml>. Acesso em: o6 de jan. de 2018. 
O manual que auxiliou os estudantes paulistas nas ocupações foi inspirado pelo movimento secundarista chileno, que, em dois momentos, em 2006 e 2011, se organizou para protestar pelo passe livre e por educação pública de qualidade. As duas principais orientações eram realizar uma assembleia geral - instância mais importante, lugar de deliberação - e, segundo, nomear comissões para cada tarefa (segurança, comida, imprensa, limpeza). Segundo a reportagem da Folha, os "alunos caminham pelas escolas usando plaquinhas penduradas no pescoço". A primeira escola ocupada foi a escola estadual Diadema, seguida da escola estadual Fernão Dias. Um aluno da Fernão Dias confessou ao jornalista: "a gente conversava com o pessoal de Diadema pelo Whatsapp. Sabíamos que ia acontecer lá também [ocupação]”.

Após as ocupações da Diadema e da Fernão, outras escolas também foram ocupadas. Essas ocupações foram assessoradas em boa parte pela ajuda dos estudantes que ocuparam as primeiras escolas. Os estudantes mais "experientes" recebiam outros estudantes que desejavam ocupar sua escola. Através dessa estratégia, a forma de ocupar escolas se propagou muito rápido, de maneira que, em um mês, foram aproximadamente 200 ocupações. Foi comum a troca de experiências entre estudantes no período das ocupações. O jornal $O$ Globo ${ }^{31}$ publicou notícia em que a estudante Ana Júlia, secundarista do Paraná, visitou o Colégio Pedro II, no Rio de Janeiro, para "uma roda de conversa" sobre as ocupações.

Além de passeatas e ocupações, os estudantes realizavam o "trancaço"32: ações relâmpago que consistiam em levar cadeiras para os cruzamentos e sentar. Essas ações confundiam a polícia, pois os estudantes ficavam correndo de cruzamento em cruzamento, desviando da repressão policial. O lema "hoje a aula vai ser na rua" embalava o protesto estudantil. O jornal O Globo publicou notícia afirmando existir um

\footnotetext{
${ }^{31}$ GUIMARÃES, Ana Cláudia. A estudante Ana Júlia esteve hoje no Colégio Pedro II no Humaitá. O GLOBO, Rio de Janeiro, 18 de nov. de 2016. Disponível em: <https://blogs.oglobo.globo.com/ancelmo/post/estudante-ana-julia-esteve-hoje-no-colegio-pedro-ii-nohumaita.html>. Acesso em: o6 de jan. de 2018.

${ }^{32}$ Protesto de alunos fecha cruzamento da Teodoro com Henrique Schaumann. FOLHA DE SÃO PAULO, São Paulo, 02 de dez. de 2015. Disponível em: $<$ https://www1.folha.uol.com.br/educacao/2015/12/171403o-protesto-de-estudantes-volta-a-fecharavenidas-em-sao-paulo.shtml>. Acesso em: o6 de jan. de 2018. RODRIGUES, Artur. Em 'dança das cadeiras', alunos escapam da PM e discutem com motoristas. FOLHA DE SÃO PAULO, São Paulo, 03 de dez. de 2015. Disponível em: <https://wwwi.folha.uol.com.br/educacao/2015/12/1714554-em-danca-dascadeiras-pelas-ruas-alunos-despistam-pm-e-discutem-com-motoristas.shtml>. Acesso em: o6 de jan. de 2018.
} 
manual para orientar como travar uma avenida: "escolha uma avenida próxima à escola e que seja bastante movimentada. De preferência, faça o ato pela manhã, entre as 6 h e as 9h. Se for um cruzamento de duas avenidas, melhor ainda!"33. Segundo a matéria, esse material foi elaborado pelo coletivo O Mal-Educado.

\section{Ocupações das escolas no Brasil, no Chile e as Jornadas de Junho de 2013}

A publicação do dia 16/12/2015 $5^{34}$, no jornal $O$ Globo, fez referência às manifestações de junho de 2013 no Brasil e do movimento dos estudantes chilenos, nos quais destaca o perfil heterogêneo dos participantes e a importância da exposição dada pela mídia para a formação da opinião pública.

Alguns artigos que tratam do movimento chileno também trazem elementos que são semelhantes ao fenômeno das ocupações no Brasil. No artigo Constantes en los movimientos estudiantiles latinoamericanos: aproximación a partir del caso chileno de 2011, Andrés Donoso Romo (2017) destaca certo padrão na forma de organização dos movimentos estudantis. Geralmente, eles são motivados pela insatisfação com a qualidade dos serviços prestados pelo Estado; articulam-se a partir de grêmios e coletivos, vinculados ou não a uma ideologia político-partidária; são movimentos heterogêneos e dinâmicos, próprios da faixa etária dos seus componentes. No caso dos estudantes de 2006, conhecido como Revolta dos Pinguins, observa-se uma exceção no que se refere à relação com grêmios e coletivos com vínculos partidários. A característica mais autônoma e horizontal dos estudantes de 2006 destoa do padrão comumente apresentado pelos movimentos estudantis no Chile. Embora o movimento de 2011, que foi uma manifestação organizada por universitários, tenha a participação de vários estudantes que eram secundaristas em 2006, verifica-se certa especialização nas

\footnotetext{
33 ROSSI, Marina. Secundaristas se organizam com "manual de como travar uma avenida". O GLOBO, Rio de Janeiro, o1 de dez. de 2015. Disponível em: <http://noblat.oglobo.globo.com/geral/noticia/2015/12/secundaristas-se-organizam-com-manualdecomo-travar-uma-avenida.html>. Acesso em: 10 de jun. de 2018.

34 BÜLOW, Marisa Von. O novo movimento estudantil e suas lições. O GLOBO, Rio de Janeiro, 16 de dez. de 2015. Disponível em: <http://noblat.oglobo.globo.com/artigos/noticia/2015/12/o-novomovimento-estudantil-e-suas-licoes.html>. Acesso em: o6 de jan. de 2018.
} 
estratégias de ação. Por isso, 2011 repete o padrão comum de ação dos movimentos estudantis chilenos.

A utilização das redes sociais e aplicativos de mensagem também contribuíram para organização e difusão das informações. No artigo El movimiento estudiantil chileno (2006-1016) y el uso de la web social: nuevos repertórios de acción e interacción comunicativa, Camila Cárdenas (2016) aborda o tema do ciberativismo no contexto dos movimentos estudantis no Chile. Os meios de comunicação, segundo Cárdenas (2016), possuem duas funções: a primeira é pragmática, "organizar eventos de massa, estabelecer táticas de ocupação e resistência contra a repressão policial e a vigilância do governo, e obter informações sobre protestos em andamento e outras influentes conjunturas políticas" (p. 96); a segunda é semântica,

identificar internamente o grupo e diferenciar dos outros grupos, refletir sobre as questões que são relevantes para garantir a coesão do grupo e o curso das mobilizações, e discutir as diretrizes ideológicas que enquadram as estratégias de interpretação e ação coletiva (CÁRDENAS, 2016, p. 96).

A autora estabelece dois critérios de reflexão para seu estudo: a análise dos repertórios de ação disponíveis nas estruturas de oportunidades políticas e a análise dos repertórios de interação comunicativa disponíveis nas estruturas de oportunidades midiáticas. Enquanto as estruturas de oportunidades políticas estão vinculadas aos sistemas políticos institucionalizados que influenciam "as possibilidades da ação coletiva e as formas que ela adota em virtude das variáveis que intervêm na constituição de atores e redes" (CÁRDENAS, 2016, p. 96-97), as estruturas de oportunidades midiáticas complementam as estruturas de oportunidades políticas, “já que, no cenário atual, é inescapável atender à capacidade dos movimentos sociais para obter visibilidade e coesão do grupo, desenvolvendo formas diárias de contenção e contestação on-line" (CÁRDENAS, 2016, p. 96-97). As ocupações chilenas representam uma etapa nova no modelo de ação coletiva, por se especializar em duas frentes de ação, a pragmática pelos meios disponíveis e já conhecidos - e a semântica, através das redes sociais. Não obstante, destacam-se pelas performances diferenciadas "de carácter mais criativos, que incluem desfiles com grupos musicais, improvisações dramáticas, corpos pintados, bonecas gigantes, máscaras e fantasias” (CÁRDENAS, 2016, p. 99). 
O discurso negativo em relação ao movimento estudantil foi bastante evidente. No artigo Representación mediática de la acción de protesta juvenil: la capucha como metáfora, Camila Cárdenas e Carolina Pérez (2017) abordam a construção do discurso em relação às ocupações chilenas, por parte da mídia, que vinculava o movimento dos estudantes com os atos dos Black-Blocks. Por isso, o movimento foi caracterizado como criminoso, com táticas terroristas. As autoras partiram de uma reportagem intitulada Radiografía a los colectivos estudiantiles "em que a atribuição de grupos radicais ao movimento estudantil foi abordada, e eles foram implicados como supostos autores do bombardeio" (CÁRDENAS; PÉREZ, 2017, p. 1.069). A tática de deslegitimação compõe um dos instrumentos do repertório de ação do governo aliado com a mídia local. A partir disso, as autoras descrevem as perspectivas que são comuns na estratégia de deslegitimação: primeiro, a construção do consenso, pela distorção dos fatos, por previsões pessimistas para o futuro e pela eleição de símbolos para depreciação do movimento, por exemplo, os Black-Blocks (encapuzados). Segundo, definição de padrões para protestos, pelo enquadramento das notícias, pela utilização de fontes oficiais que fortalecem o discurso da mídia, pela invocação da opinião pública, pela desqualificação dos membros e condenação das pautas dos movimentos estudantis (CÁRDENAS; PÉREZ, 2017, p. 1.070). Constituiu-se, no Chile, a opinião de que o movimento de ocupações era efêmero e circunstancial.

No artigo Acontecimiento y acción colectiva juvenil. El antes, durante y después de la rebelión de los estudiantes chilenos en el 2006, Oscar Aguilera Ruiz (2011) aponta para elementos importantes dentro da teoria sobre movimentos sociais. Ele considera quatro aspectos no movimento de ocupações chilenas em 2006: primeiro, os conflitos não se concentram somente pela reivindicação de bens e serviços, mas também se dão em torno de exigência de qualidade de vida; segundo, os conflitos reordenam os processos de difusão geográfica e setorial, não pelos meios tradicionais de organização social, mas através de novos atores sociais, no caso chileno, os estudantes secundaristas; terceiro, a emergência de novos movimentos sociais que, muitas vezes, se caracterizam por ações espontâneas e pouco articuladas; quarto, a construção de novos significados culturais que, pouco a pouco, passam a constituir parte da cultura política dos sujeitos e dos movimentos (TARROW, 2002 apud RUIZ, 2011, p. 13). Esses quatro aspectos foram 
observados a partir de uma leitura da organização dos estudantes chilenos de 1999 até o pós-ocupações de 2006. Nesse aspecto, o autor trabalhou com a categoria de Tarrow “ciclo de mobilização”, que trata dos repertórios e performance de ação.

Os eventos do Chile, de junho de 2013, e as ocupações das escolas no Brasil têm em comum a ação descentralizada e a crítica às instâncias tradicionais de representação. A Folha de São Paulo, em publicação do dia 25/11/2015 $5^{35}$, também deu destaque às estratégias de ação dos estudantes brasileiros com clara referência ao movimento chileno. A resistência dos estudantes brasileiros à participação de coletivos estudantis como UNE e Ubes, ou de grupos vinculados a partidos políticos foi outro destaque ${ }^{36}$. Os jovens estudantes, que formavam em quase sua totalidade o conjunto dos participantes, optavam pelo estilo de ação direta, sem a necessidade de convocação de movimentos e partidos.

A Folha de São Paulo, em notícia do dia 11/12/2015 e 14/12/2015 $5^{38}$, comparou a reivindicação dos estudantes de Goiás com as dos estudantes Chile em 2006 e 2011. No caso chileno, a pauta pelo acesso à educação pública e o passe livre, como também a crítica à participação de organizações sociais privadas na gerência da educação, foram recordadas pelas ocupações das escolas em Goiás, contrárias ao projeto do Governo Perillo, de passar a gerência da educação para OS. Conforme dados disponibilizados por Carolina Álvares-Valdéz e Antonia Garcés-Sotomayor, a pauta motivadora das ocupações das escolas chilenas, em 2006 e 2011, questionava o modelo administrativo público-

35 MACHADO, Leandro. Inspirado no Chile, manual orientou ocupação de escolas por alunos em SP. FOLHA DE SÃO PAULO, São Paulo, 25 de nov. de 2015. Disponível em: $<$ https://www1.folha.uol.com.br/educacao/2015/11/1710710-inspirado-no-chile-manual-orientouocupacao-de-escolas-por-alunos-em-sp.shtml>. Acesso em: o6 de jan. de 2018.

${ }^{36}$ GRAGNANI, Juliana; MACHADO, Leandro. Alunos de ocupações expulsam grupo estudantil ligado a partido. FOLHA DE SÃO PAULO, São Paulo, $11 \mathrm{de}$ dez. de 2015. Disponível em: <https://wwwi.folha.uol.com.br/educacao/2015/12/1717674-alunos-de-ocupacoes-expulsam-grupoestudantil-ligado-a-partido.shtml>. Acesso em: o6 de jan. de 2018.

37 BATISTA, Diene. Contra plano de governador tucano, estudantes ocupam escolas de Goiânia. FOLHA DE SÃO PAULO, São Paulo, 11 de dez. de 2015. Disponível em: $<$ https://www1.folha.uol.com.br/educacao/2015/12/1717898-contra-plano-de-governador-tucanoestudantes-ocupam-escolas-de-goiania.shtml>. Acesso em: o6 de jan. de 2018.

$3^{8}$ BATISTA, Diene. Em Goiás, alunos ocupam escolas no interior contra 'terceirização'. FOLHA

DE SÃO PAULO, São Paulo, 14 de dez. de 2015. Disponível em: <https://www1.folha.uol.com.br/cotidiano/2015/12/1718878-em-goias-alunos-ocupam-escolas-nointerior-contra-terceirizacao.shtml>. Acesso em: 06 de jan. de 2018. 
privado de investimento em educação. Afirmavam que ele estruturava a desigualdade social no Chile.

A Folha ainda deu ênfase à participação dos jovens em mobilizações anteriores às ocupações. Conforme notícia do dia 17/01/201639, alguns dos jovens que protagonizaram as ocupações em 2015 começaram a militância com as Jornadas de Junho de 2013. Agora, esses mesmos jovens compõem o Movimento Passe Livre (MPL). Apesar do trânsito - Jornadas de Junho de 2013, Ocupações das Escolas, Movimento Passe Livre - a recusa dos estudantes pela centralização das decisões caracteriza "uma ojeriza à especialização”.

Em 2016, com a segunda onda de ocupações de escolas no Brasil (a primeira foi em 2015, em São Paulo e Goiás), diversos movimentos manifestaram apoio: Movimento Passe Livre, Mal Educado, Diretório Central dos Estudantes da USP e grupos relacionados às ocupações de $2015^{40}$. A pauta comum afirmava o desejo de "mais democracia e serviços de melhor qualidade" 4 .

\section{Agenda de discussões?}

As ocupações foram motivadas por diversas pautas: em São Paulo, contra o fechamento e a reorganização das escolas, em 2015 e em 2016, pela falta de merenda em escolas do ensino integral e o corte no orçamento da educação; em Goiás contra o projeto das OS do Governo Perillo; no Rio, em apoio à greve dos professores e por melhorias nas escolas - material didático, merenda, infraestrutura -; no Rio Grande do Sul, pelo repasse em dia da verba de autonomia das escolas e a defesa do ensino público de qualidade; além da pauta comum de todas as ocupações em 2016, contra a PEC do

39 RODRIGUES, Artur; BERGAMIM JR, Giba; MACHADO, Leandro. Movimento Passe Livre tem linha de frente mais 'teen' nos atos deste ano. FOLHA DE SÃO PAULO, São Paulo, 17 de jan. de 2016. Disponível em: <https://wwwi.folha.uol.com.br/cotidiano/2016/o1/1730391-movimento-passe-livre-temlinha-de-frente-mais-teen-nos-atos-deste-ano.shtml>. Acesso em: o6 de jan. de 2018.

$4^{40}$ LOBEL, Fabrício; GOMES, Paulo. Movimentos de esquerda fazem ato em apoio a alunos de ocupações em SP. FOLHA DE SÃO PAULO, São Paulo, 13 de maio de 2016. Disponível em: <https://www1.folha.uol.com.br/cotidiano/2016/05/1771161-movimentos-sociais-fazem-ato-em-apoio-aalunos-de-ocupacoes-em-sp.shtml>. Acesso em: o6 de jan. de 2018.

${ }^{41}$ SETUBAL, Maria Alice. Jovens dão aula de cidadania. FOLHA DE SÃO PAULO, São Paulo, o6 de dez. de 2015. Disponível em: <https://www1.folha.uol.com.br/opiniao/2015/12/171530o-jovens-daoaula-de-cidadania.shtml>. Acesso em: 06 de jan. de 2018. 
Teto de Gastos, a Reforma do Ensino Médio e a crítica ao projeto Escola Sem Partido. Entretanto, houve outras pautas de debate no interior do movimento.

A primeira foi a distribuição das tarefas por comissões. Essa estratégia favoreceu a organização dos estudantes durante o período da ocupação. Dessas comissões, surgiram ações para manutenção da própria escola: pintura das paredes, limpeza dos espaços, como registra reportagem do dia 01/12/2015 ${ }^{42}$ da Folha de São Paulo, "nunca vi a escola tão limpa assim". O ato de ocupar a escola também revelou problemas estruturais, que não é possível perceber somente pela frequência nas aulas. Por exemplo, os alunos "descobriram espaços sem uso, como sala cheia de cadeiras e mochilas novas e um vestuário com capacidade para oito chuveiros, que havia virado almoxarifado. Foi nele que os alunos instalaram dois chuveiros”. O protagonismo das meninas na organização das tarefas também foi destacada pela Folha de São Paulo, em notícia do dia $03 / 07 / 2016^{43}$.

A segunda pauta, abordada nas oficinas e aulas públicas, tratavam do "feminismo, diversidade social e racismo"44, "educação sexual, igualdade racial e social45", com a presença de artistas, professores universitários e líderes de movimentos sociais. A questão levantada pelos estudantes era de que a escola poderia ir além das salas de aula. A assembleia, instância mais importante nas ocupações, deliberava sobre quais aulas queriam ter. Várias dessas oficinas e atividades culturais eram marcadas através das redes sociais ${ }^{46}$.

\begin{tabular}{llll}
\multicolumn{1}{c}{${ }^{42}$ Há um mês na escola, alunos limpam, cozinham e até instalam chuveiros. FOLHA DE SÃO } \\
PAUlO, São Paulo, ol de dez. de 2015. Disponível em:
\end{tabular} <https://www1.folha.uol.com.br/educacao/2015/12/1712999-ha-um-mes-nas-escolas-alunos-organizamlimpam-cozinham-e-ate-instalam-chuveiros.shtml>. Acesso em: o6 de jan. de 2018.

43 TERENZI, Gabriela; SALDAÑA, Paulo. Fortalecidos após ocupações, secundaristas de SP renegam entidades estudantis. FOLHA DE SÃO PAULO, São Paulo, o3 de jul. de 2016. Disponível em: <https://www1.folha.uol.com.br/saopaulo/2016/o7/1787761-fortalecidos-apos-ocupacoes-secundaristasde-sp-renegam-entidades-estudantis.shtml>. Acesso em: o6 de jan. de 2018.

${ }^{44}$ TERENZI, Gabriela; SALDAÑA, Paulo. Fortalecidos após ocupações, secundaristas de SP renegam entidades estudantis. FOLHA DE SÃO PAULO, São Paulo, o3 de jul. de 2016. Disponível em: $<$ https://wwwi.folha.uol.com.br/saopaulo/2016/o7/1787761-fortalecidos-apos-ocupacoes-secundaristasde-sp-renegam-entidades-estudantis.shtml>. Acesso em: o6 de jan. de 2018.

45 Souza, Felipe. Agenda cultural em colégios ocupados inclui circo, debate e até cursinho. FOLHA DE SÃO PAUlO, São Paulo, 27 de nov. de 2015. Disponível em: $<$ https://www1.folha.uol.com.br/educacao/2015/11/1711764-agenda-cultural-em-colegios-ocupados-incluicirco-debate-e-ate-cursinho.shtml>. Acesso em: o6 de jan. de 2018.

${ }^{46}$ BATISTA, Diene. Contra plano de governador tucano, estudantes ocupam escolas de Goiânia.

FOLHA DE SÃO PAUlO, São Paulo, 11 de dez. de 2015. Disponível em: 


\section{Balanço das vitórias e derrotas das pautas dos estudantes}

Em São Paulo, lugar onde as primeiras ocupações ocorreram, o protesto contra o fechamento de 92 escolas e remanejamento dos estudantes obteve resultado positivo para os docentes. O Governo Alckmin voltou atrás no projeto e prometeu estabelecer diálogo com a comunidade escolar.

No Rio de Janeiro, a principal conquista foi o acolhimento da demanda dos estudantes e professores da rede estadual para eleição dos diretores. Antes os diretores eram indicados pela Secretaria de Educação através de um processo interno, sem a participação da comunidade escolar. Outras conquistas também foram contabilizadas, no que se refere ao suporte financeiro para melhorias estruturais das escolas que foram ocupadas.

Em Goiás, o protesto dos estudantes não obteve sucesso. A pauta estudantil desejava barrar o projeto do Governo Perillo de transferir a gestão das escolas para OS. Nas ocupações de outros estados, que protestavam contra a Reforma do Ensino Médio e contra a PEC do Teto de Gastos, o objetivo não foi alcançado. A PEC já está em vigor desde 2017, e o decreto da Reforma do Ensino Médio já foi publicado, com prazo para adaptação das escolas, como também dos exames em nível federal ou estadual, que contam com a base curricular comum. Porém, apesar das derrotas, criou-se uma rede de contatos entre estudantes que fortaleceu o movimento estudantil.

\section{Considerações finais}

As ocupações das instituições de ensino têm um perfil contestador. Resultam da insatisfação dos pais, alunos e professores com a falta de investimento na educação pública. De um lado, os artigos acadêmicos ressaltaram o significado político das ocupações, em especial, os temas mais voltados para agenda identitária e pela estratégia

$<$ https://wwwl.folha.uol.com.br/educacao/2015/12/1717898-contra-plano-de-governador-tucanoestudantes-ocupam-escolas-de-goiania.shtml>. Acesso em: 06 de jan. de 2018. 
de automobilização ${ }^{47}$. Por outro lado, os jornais consultados descreveram o processo de ação a partir da animosidade entre os estudantes e o poder público. Não obstante, chamo atenção para o alto número de instituições ocupadas e o rápido processo de articulação dos estudantes. Tudo isso dentro de um contexto político conturbado de crise econômica e denúncias de corrupção.

Como chave de leitura para compreender a ação dos estudantes em 2015 e 2016, parto do alerta de Inglehart e Welzel (2009) sobre o papel dos movimentos de massa dentro de um contexto de transição ou sobrevivência de um regime político:

(...) muitos pesquisadores têm argumentado que ações coletivas geridas pelas elites compõem sempre a causa imediata das transições de regimes para democracia. Consequentemente, as transições para democracia podem ser vistas como resultado de jogos de ataque e defesa entre as elites governantes e as contraelites que as desafiam (...) regimes democráticos são estáveis se as elites concordam que a democracia é a única opção possível (p. 26o).

Segundo o autor, os teóricos - cientistas políticos e afins - têm concedido relevante papel às elites quando se trata da mudança ou sobrevivência dos regimes políticos. É no nível delas que as negociações se dão e os movimentos de massa representam um anexo importante, mas não definitivo. A noção segundo a qual os interesses em disputa são resolvidos no nível das elites reduz a participação política à conquista do poder. Conforme Inglehart e Welzel (2009), essa visão "enfoca de forma limitada as causas adjacentes da democratização, ignorando as forças sociais mais amplas que canalizam” as ações coletivas numa direção específica (p. 260).

Inglehart e Welzel (2009) fazem uso de dois termos para explicar a mudança ou sobrevivência dos regimes políticos. O primeiro, eles chamam de variável cumulativa, que se caracteriza pelo longo processo histórico de uma sociedade, sua herança cultural e as mudanças gradativas que sofreu no campo político, econômico e social. O segundo termo, de variável de ruptura que se refere a eventos que ocorrem de maneira abrupta, explosiva e se caracterizam por alterações drásticas na ordem vigente. Segundo os

47 “Automobilização" foi o conceito empregado por Manuel Villaverde Cabral (2003) para tratar de formas não institucionalizadas de mobilização social. Podem-se usar outros termos como "formas de ação não convencional" (BORBA, 2012) ou "ações diretas, não institucionalizadas" (INGLEHART; WELZEL, 2009). Estes termos dizem respeito aos atos de protestos que se caracterizam por um leque de ações disponíveis. 
autores, só há relação entre as duas variáveis quando uma delas, a variável de ruptura, surge. Em outras palavras, não é possível afirmar que a variável cumulativa é a causa da variável de ruptura. Contudo, é possível verificar se os eventos e modificações resultantes do processo de ruptura podem sobreviver a partir da variável cumulativa. Inglehart e Welzel (2009) explicam que essas condições são permeadas por forças sociais que direcionam as ações coletivas para uma direção específica. As forças sociais concentram os elementos que podem ser classificados por orientações materialistas ou pós-materialistas. Para o autor, essas forças sociais têm um caráter modernizador e entram em conflito com os elementos tradicionais de uma sociedade. Diante disso, quando ocorre uma ruptura, explodem também as contradições ou polarizações que mobilizam diversos grupos sociais.

O recente contexto brasileiro registrou alguns eventos que merecem destaque. O primeiro deles, as Jornadas de Junho de 2013, tinha um perfil altamente heterogêneo e pautas políticas diversas. Dentre os temas em discussão, ressalto a demanda por acesso a serviços públicos de qualidade e o desgaste com a elite política. Os anos de 2014 e 2015 se caracterizaram pelo adensamento da polarização PT e PSDB, que depois viria a se tornar petismo e antipetismo, resultado das eleições em que Dilma Rousseff foi reeleita como presidente da República. As ondas de manifestações pró ou contra o governo de Dilma Rousseff culminaram no processo de impeachment no ano de 2016. Essa ruptura com a ordem democrática pode ser considerada um marco político importante, dentro do qual também está inserido o processo de ocupação das escolas (2015-2016). Portanto, esses últimos anos podem ser compreendidos por um processo de transição política, no qual as manifestações de massa tiveram um papel central. O desafio do pesquisador é desvendar quais forças sociais permeiam esse processo de transição e o que se pode esperar para o futuro.

A análise das ocupações das escolas pode fornecer algumas pistas sobre quais forças sociais estão mobilizando variados grupos da sociedade brasileira, quais elementos modernizadores e tradicionais estão em conflito e quais orientações políticas estão em questão. 


\section{Referências}

ÁLVAREZ-VALDÉZ, Carolina; GARCÉS-SOTOMAYOR, Antonia. La construcción de generación en los discursos juveniles del Chile actual. Revista Latinoamericana de Ciencias Sociales, Niñez y Juventud, v. 15, n. 2, p. 991-1004, 2017.

AVENDAÑO, Octavio. Fracturas y representación política en el movimiento estudiantil: Chile 2011. Ultima década, v. 22, n. 41, p. 41-68, 2014.

BORBA, Julian. Participação política: uma revisão dos modelos de classificação. Sociedade e Estado, v. 27, n. 2, p. 263-288, 2012.

CABRAL, Manuel Villaverde. O exercício da cidadania política em perspectiva histórica (Portugal e Brasil). RBCS, v. 18, n. 51, p. 31-6o, 2003.

CÁRDENAS, Camila; PÉREZ, Carolina. Representación mediática de la acción de protesta juvenil: la capucha como metáfora. Revista Latinoamericana de Ciencias Sociales, Niñez y Juventud, v. 15, n. 2, p. 1067-1084, 2017.

CÁRDENAS, Camila. El movimiento estudiantil chileno (2006-2016) y el uso de la web social: nuevos repertorios de acción e interacción comunicativa. Ultima década, v. 24, n. 45, p. 93-116, 2016.

CARNEIRO, Silvio. Ocupar, resistir e a luta nas redes sociais. Comunicações, v. 24, n. 2, p. 137-150, maio-agosto, 2017.

CORTI, Ana Paula de Oliveira; CORROCHANO, Maria Carla; SILVA, José Alves da. "Ocupar e resistir": a insurreição dos estudantes paulistas. Educação \& Sociedade, v. 37, n. 137, p. 1159-1176, 2016

FLEET, Nicolás. Movimiento estudiantil y transformaciones sociales en Chile: una perspectiva sociológica. Polis. Revista Latinoamericana, n. 30, p. 99-116, 2011

GIROTTO, Eduardo Donizeti. A dimensão espacial da escola pública: leituras sobre a reorganização da rede estadual de São Paulo. Educação \& Sociedade, v. 37, n. 137, p. 1121-1141, 2016

INGLEHART, Ronald; WELZEL, Christian. Modernização, mudança cultural e democracia: a sequência do desenvolvimento humano. São Paulo: Francis, 2009.

JANUÁRIO, Adriano et al. As ocupações de escolas em São Paulo (2015): autoritarismo burocrático, participação democrática e novas formas de luta social. Revista Fevereiro, n. 9, p. 1-26, 2016. 
JUNQUEIRA, Marili Peres. Primavera secundarista: as ocupações nas escolas estaduais públicas de Uberlândia-MG em 2016. Teoria e Cultura, v. 12, n. 1, p. 149-162, 2017.

ROMO, Andrés Donoso. Constantes en los movimientos estudiantiles latinoamericanos: Aproximación a partir del caso chileno de 2011. Revista Historia de la Educación Latinoamericana, v. 19, n. 28, p. 71-90, 2017.

RUIZ, Oscar Aguilera. Acontecimiento y acción colectiva juvenil. El antes, durante y después de la rebelión de los estudiantes secundarios chilenos en el 2006. Propuesta Educativa, n. 35, p. 11-26, 2011.

SEGURADO, Rosemary; SANTOS, Marcelo Burgos Pimentel. Ocupação dos espaços públicos e a produção do comum: a ação política dos estudantes secundaristas nas escolas públicas de São Paulo. In: 4oo Encontro Anual da ANPOCS. Anais, ST13. Hotel Glória, Caxambú (MG), 2016, p. 1-22.

SILVA, Bárbara Virgínia Groff da; SILVA, Eduardo Cristiano Hass da. "Uma pá de ocupação": ocupações escolares e atuação juvenil no Rio Grande do Sul. Revista Teias, v. 18, n. 50, p. 228-244, 2016.

SILVA, Caio Ramos da; SILVA, Danielle Miranda da; ROSÁRIO, Nísia Martins do. Ocupações dos secundaristas do RS: tensões culturais e reconfigurações comunicativas. Intexto, n. 37, p. 193-214, set-dez 2016. 